\title{
Research on the Professional Development Path of Sanda in Contemporary China
}

\author{
Peilei Cao \\ P.E Faculty, Haikou College of Economics, Hainan, 571127
}

\begin{abstract}
This paper studies the issues of Sanda professionalization in China by means of literature, interview and mathematical statistics, points out the current situation of professional development of Sanda, analyzes the problems of Sanda professionalism and puts forward the countermeasures of Sanda professional development. And we also provide a theoretical basis for proposing a new strategy to promote the theoretical study of Sanda professional practice and exploration.

Keywords professional development path, Sanda, contemporary China
\end{abstract}

\section{Introduction}

Sanda is an important part of the Chinese martial arts, which is one of the modern competitive sports that the two men use the techniques of kicking, playing, throwing and other offensive and defensive techniques to conquer each other according to certain rules. Chinese martial arts movement only to professionalism can be faster to improve visibility, improve the level, so as to enter the Olympic Games. Sanda is a traditional Chinese sports, but the Sanshou it raised it in the land is not a real professional tournament, but no way to talk about the enormous influence of the international. This is also the Sanda at the door held in the 2008 Beijing Olympic Games was only set for the Olympic Games during the performance project has not been set for the Olympic Games one of the reasons for the official event. Professionalization is conducive to improving the level of competitive sports, professional training and competition can be directly linked with the material interests, is conducive to mobilize the majority of coaches, 
athletes enthusiasm, professionalism also allows athletes during training, and even retired life be Of the guarantee to solve the athletes to worry about, and then stimulate the intrinsic motivation of athletes, which in the invisible to extend the athlete's life and so on. Therefore, if the Sanda to be substantial, improve visibility, if Sanda to significantly improve the level of movement, if Sanda to enter the Olympic Games, it must be the direction of professionalism.

\section{The development of Sanda movement}

Sanda, also known as Sanshou, it is the most simple Chinese martial arts strokes extracted, quickly knock down the opponent's competitive sports, and therefore represents the martial arts martial arts essence. However, the time that Sanda is known to the world is not long, and the formation of competitive system is only in the past 20 years. In 1978, the state formally put forward the Sanda pilot work; the second year, began to pilot training, in the "positive, prudent and secure" approach to development gradually formed a ring for the national characteristics, to kick, fight, fall as the main technical content In 1991, Sanda to become the world championships; in 1998, Sanda into the Asian Games, after more than 20 years of competition, more than 20 kinds of competitions in the country, Year of the summary, improvement and development, Sanda has become a modern sports competition projects, and gradually with the international competitive sports convergence.

\section{The major obstacles of the current professional development of China Sanda}

\subsection{Competition System.}

At present, the provincial Sports Bureau, Sanda professional team to the annual national competition as the main task, Sanda Club League Challenge Cup and some commercial games are placed in a secondary position. But the former because the schedule is short, lack of publicity, the audience less, a variety of media are less reported, so the business, business attraction is not, while the latter audience, media, business attention and participation more. Therefore, in the current competition system, there has been such a contradiction, the market need goods, in the manufacturer point of view, not the most important, and the market does not like the goods is the most valued manufacturers. Sanda to go professional road to develop the market, this race system caused by the contradiction between the market supply and demand, we must find a solution.

\section{2 Provision}

Sanda once transferred to the professional development of the professional club funding sources and now Sanda professional team funding sources, compared to 
certainly will change. First of all, the higher the allocation will be canceled; In addition, looking for cooperation with the club to provide large financial sponsorship or direct investment in the club's business enterprises, is not an easy task. In particular, the first two years of the club's operating funds to raise will be placed in front of the club operators a serious problem.

\subsection{The club management}

Professional Sanda club in order to develop a good, it is best not only familiar with Sanda professional and proficient in business management personnel management of the club, but at present this talent is also very few, but also no specialized training of such personnel, the lack of This specialized personnel may be on the club's own business management adverse impact.

\subsection{Marketing is not enough and the basic audience is not formed}

For a long time, Chinese sports is taking the sports model, the athletes are basically funded by the government training, the state invested a lot of competitive sports human and material resources, resulting in a bias is the national sports, but really participate in sports Is a very small part of the movement elite. In the development of Sanda, we can see all the rules, games, training, but do not see the participation of ordinary people, which does reflect a phenomenon is the Sanda audience No form, in this case, the emergence of Sanda King Competition Although the beginning can cause a sensation, people because of fresh or national complex to look at, but after the enthusiasm will cool down, Sanda has not been popular, events There is no market. During the development of Sanda, we did not aim to popularize the sport.

\subsection{The management system is not perfect}

The reform of Chinese market economic system is still in the planned economy to market economy transition stage, professional sports reform is lagging behind the economic system reform. China Wushu Association has been a supporting role in the market since its inception, and has not played the role of self-management, self-financing, despite the martial arts association in recent years made great efforts, but by the institutional constraints, Subjective and objective factors, the management system, there are still a series of problems: (1) management system is not perfect. With the establishment of the socialist market economy and the emergence of the individual management center of the sports project compared with the original planned economy system, the individual sports association is the only one which is responsible for the management of the professional sports in our country. But after all, has just come out from the original government departments to a large extent leave any traces of the Government, its functions are also more vague, not only responsible for the formulation of policies and regulations, but also responsible for market-oriented project management, but also responsible Improve the level of Chinese athletic sports, and achieved excellent results. This management system and the market does not adapt, is the 
impact of Sanda into the professionalism of the important reasons. (2) the lack of an independent legal personality of the Sanda sports operating entity. From the current point of view can really take on the autonomy of self-financing professional events of the units is still lacking from the operation of Sanda King Competition situation, the government agencies and private sports companies Coorganized, the involvement of sports intermediaries makes the operation of the tournament more market-oriented law, but because the government still has influence on the operation, so that the event is still largely a governmententerprise. (3) the lack of understanding of Sanda, understand business, to understand the management of specialized personnel. Sanda professional development has just started, the school is the lack of understanding of the development and management of people, which led to the waste of resources, the value of the blind development of athletes and randomness.

\section{The professional development path of contemporary China Sanda}

\subsection{Expand the influence of Sanda}

At present, the status quo of Chinese television media is a dominant CCTV, the strength of local television stations vary greatly, the foreign media by Chinese policy restrictions. With the special status of the national television station, as well as the difference between the strength of local television stations and national policies on foreign media restrictions and other factors, China Central Television in the domestic television media industry has a huge advantage. Sanda take the road of professionalism, we must strive to overcome the difficulties, the realization of CCTV Sports Channel (CCTV - 5) Sanda event live. Only in this way can the greatest extent to expand and enhance the influence of Sanda tournament and visibility. In addition, if the Sanda event broadcast through CCTV, not only conducive to significantly improve the Sanda competition influence and visibility, but also conducive to attract more sports sponsorship, is conducive to the brand and the value of athletes to enhance.

\section{Improve the relevant laws and regulations and develop appropriate policies}

Market economy is legal economy and the healthy development of market economy must have a complete legal system for protection. Since the reform of the market economy, various laws and regulations have been put forward, but at present, the legal system of our country is not perfect, especially the laws and regulations concerning the sports field. To this end, the relevant sports legislation should speed up the process, update is not very applicable laws and regulations, and constantly improve the competitive sports market, professional sports such as human capital property rights, sports brokers, sports insurance, sports rights, sports, sports Sponsorship and other aspects of the laws and regulations. To 
develop a variety of policies conducive to the promotion of enterprises, social groups and individuals involved in investment Sanda, so as to expand Sanda professional funding sources. For example, in sports sponsorship can be developed to reduce tax or tax-free preferential policies to improve the enterprise sponsorship of sports initiative.

\subsection{Develop appropriate rules for the public Sanda}

Regardless of Sanda market or Sanda professionalism, they all need to have a broad mass base and this is the only way to have the consumer market. We know that the current Sanda movement is mainly confined to the various local Sanda professional teams, martial arts schools and sports institutions, Sanda popular popularity is still very low. In order to promote the professional development of Sanda, it is necessary to improve the mass base of Sanda to improve the popularity.

\section{Conclusion}

Today the professional sports get rapid development, Sanda professional reform faces a lot of opportunities and challenges, it is beneficial to have a lot of successful professional sports operational experience we can draw lessons from Chinese own political and economic system. But with the further strengthening of the emancipating the mind in the sports reform, in the near future, the Sanda movement will open up a suitable road with the international professional sports competition for their own development.

\section{References}

[1] The Revolution of Sanda - Chinese Wushu, 55(12), pp.68-70, 2011

[2] Zhang Youyi The Crux and Development of Sanshou, 8 (5), pp.87- 91, 2013

[3] Jiang Bailong, Yu Hongkun. The reform of the management system of free throwing hand in our country is imperative. Journal of Wuhan Institute of Physical Education, 12(10), pp. 18- 20, 2012

[4] Zhao Changjun, Development of the old professional sports industry and its enlightenment. Journal of Physical Education, 9(6), pp.58- 61, 2011

[5] Guo Qi, A Study of the Wushu Schools in China, Sports Science, 8(4), pp.8587, 2014 